\title{
Age and sex-related associations between marital status, physi- cal activity and TV time
}

\author{
Timothy Gustavo Cavazzotto ${ }^{1}$, Natã Gomes de Lima Stavinski ${ }^{2}$, Marcos Roberto Queiroga ${ }^{1}$, Michael Pereira da \\ Silva ${ }^{3}$, Edilson Serpeloni Cyrino ${ }^{4}$, Helio Serassuelo Junior ${ }^{5}$ and Edgar Ramos Vieira ${ }^{6, *}$
}

1 Department of Physical Education, Midwestern Parana State University, Guarapuava, Parana, Brazil; consultoriacvzt@gmail.com (TGC); queirogamr@hotmail.com (MRQ)

2 Graduate Program in Health Sciences, Center of Health Sciences, State University of Londrina, Londrina, Parana, Brazil; natavinski@hotmail.com

3 Graduate program in Public Health, Faculty of Medicine, Federal University of Rio Grande, Rio Grande, Rio Grande do Sul, Brazil. mpsilva@furg.br

4 Department of Physical Education, Faculty of Physical Education and Sport, State University of Londrina, Londrina, Parana, Brazil; edilsoncyrino@gmail.com

5 Department of Sports Science at the State University of Londrina, Londrina, Parana, Brazil; heliojr@uel.br

6 Department of Physical Therapy, Florida International University, Miami, Florida, USA; evieira@fiu.edu

* Correspondence: natavinski@hotmail.com

\begin{abstract}
We aimed to identify the age and sex-related associations between marital status with PA and TV time. We used data from Vigitel, an annual telephone survey started in 2006 in Brazil. We applied a complex sample logistic regression model to estimate the odds for PA and TV time comparing marital statuses according to age and sex subgroups, independent of obesity, hypertension, diabetes, self-assessed poor health, and smoking. Our sample included 561,837 individuals with a TV time $>3 \mathrm{~h} /$ day (prevalence $=25.2 \%$ ) and PA $>150 \mathrm{~min} /$ week (prevalence $=35 \%$ ). Compared to single individuals, married men and women were less likely to watch TV more than 3 $\mathrm{h} /$ day in participants $>30$ years old. When compared to single, married participants were less likely to do more than $150 \mathrm{~min}$ of PA/week at younger age groups. Married women older than 40 years were more likely to do more than $150 \mathrm{~min}$ of PA/week than the single ones, while there were no differences among married men by age group. In conclusion, married individuals are less likely to spend more than 3 hours a day watching TV than single individuals. Single men and women were more likely to do more than $150 \mathrm{~min}$ of PA/week at younger age groups and married women older than 40 years were more likely to do $150 \mathrm{~min}$ of PA/week than single women.
\end{abstract}

Keywords: exercise; marriage; sedentary behavior; gender, age groups, behavioral risk factor surveillance system

\section{Introduction}

Regular physical activity (PA) practice is associated with good health outcomes, preventing the development of many of the most common non-communicable diseases [1]. On the other hand, sedentary behavior, which is sitting or reclining at an energy expenditure of 1 to 1.5 basal metabolic rates, has been associated with all-cause and cardiovascular mortality, independent of PA levels and body mass index (BMI), independently of moderate to vigorous PA [2]. Therefore, the World Health Organization (WHO) provided guidelines on PA and sedentary behavior, recommending to adults to meet between 150300 minutes of moderate-intensity PA weekly. While although there is not enough evidence on the quantitative threshold of sedentary behavior, it is recommended to limit the amount of time as much as it is possible [3]. PA and sedentary behavior (SB) are independent behaviors influenced by several correlates [4] which might not be the same for both behaviors. A critical correlate is a marital status, which has been associated with health benefits and longevity [5]. 
Recent studies investigating health influence of marital status revealed that married adults have lower morbidity, mortality risks, mental disorders, and suicide risk than unmarried people [6-8]. According to a US population-based study, marriage was associated with reducing substance use, such as tobacco, alcohol, and cannabis, compared to single and divorced/separated men [9]. In another study, Kim et al. found that living without a partner results in lower odds of smoking and drinking, while blood pressure and glycohemoglobin are lower in married [7]. These observations might be explained by the theory of social selection and the theory of social causation [10], which states that healthier people are more susceptible to get married and staying married longer. In contrast, married individuals showed lower fitness levels than single individuals [11], but there are differences between men and women. A recent population-based survey investigating health-related factors in 59,402 Brazilians found that adults with a sexual partner have 1.2 higher chances of obesity [12]. Therefore, there is some contradicting findings on the influence of marital status on physical activity and sedentary lifestyle, particularly differences between age and sex subgroups.

Twenty seven and a half percent of the world population is inactive [13] and spend substantial time in sedentary behaviors [14,15]. Marital status [11], age [16] and sex [17] are associated with health status. A prospective study investigated the association between marital status transitions and fitness level changes in men and women [11]. The study found that men transiting from single to married reduce their fitness levels. At the same time, women in this transition did not change their fitness level. However, women who remained single increased their fitness levels, supporting prior findings that indicate that married individuals practice less PA. However, there seem to be differences between men and women as well as among age groups. O'Donoghue et al. [16] conducted a systematic review to identify associations between sedentary behavior and various outcomes in adults aged 18-65 years. The review found that 14 of the 20 studies found a positive relationship between age and sedentary behavior.

Contradictions on the relationship between marital status and PA were found in a recent review of reviews. The association was deemed inconclusive in five reviews, no association was found in three reviews, and a negative association was found in one review [18]. However, those reviews analyzed specific subgroups (e.g., only adults without gender separation, only older women, etc.), which limits the analytical power to compare differences between sexes and age groups. Thus, the current study aimed to evaluate the association between marital status, PA and sedentary behavior (i.e., TV time) by age and sex groups.

\section{Materials and Methods}

\section{Sample}

We used data from the Surveillance of Risk and Protection Factors for Chronic Diseases by Telephone Survey - VIGITEL. It is a telephone survey that started in 2006 and it is annually performed in all Brazilian state capitals and the Federal District to identify the frequency, distribution, and progression of the main risk factors for chronic non-communicable diseases [19]. We used the data from 2009 to 2019 because some variables of our interest were only added in 2009.

The sampling procedures aim to obtain probabilistic samples of the adult population ( $\geq 18$ years of age) living in households with at least one phone. The system establishes a minimum sample size of approximately 2000 individuals in each city to estimate the frequency of the main risk factors for chronic non-communicable diseases (hypertension, diabetes, and dyslipidemia). The Vigitel questionnaire includes short and simple questions on demographics and socioeconomic characteristics, feeding patterns and physical activity, self-reported weight and height, tobacco and alcohol consumption, and self-evaluation of health status. 


\section{Physical activity and TV time}

To estimate PA, we used the following questions: "In the last three months, did you perform any exercise or sport?"; "What is the main type of physical exercise or sport that you practiced?"; "Do you do the exercise at least once a week?"; "How many days a week do you usually practice exercise or sport?"; "On the days you practice physical exercise or sport, how long (minutes/day) do you perform these activities?"; With the responses to these questions, we estimated the prevalence of leisure time physical activity $>150$ minutes/week.

We used the following questions to evaluate TV time: "How many days a week do you watch TV?"; "How many hours do you watch TV per day?". There were eight alternatives to answer, ranging from "less than one hour a day" to "more than six hours a day", including "I don't watch TV". With the responses to this question, we estimated TV time.

\section{Covariates}

The predictive model considered the following covariates: age, obesity, hypertension, diabetes, self-evaluation of poor health, and smoking. Obesity was evaluated based on the calculation of Body Mass Index (BMI $\geq 30 \mathrm{~kg} / \mathrm{m}^{2}=$ obesity) [20] using the aswers to the following questions: "What is your weight?", and "What is your height?."

Hypertension was evaluated based on the following question: "Have any physician ever told you that you have high blood pressure/hypertension?". Diabetes was assessed based on the following question: "Have any physicians ever told you that you have diabetes?."

Self-assessment of health status was evaluated using the following question: "How would you rate your health status?". Health was classified as poor if they answered "bad" or "very bad". Smoking was assessed by asking "Do you smoke?" independently of amount, frequently or the duration.

\section{Statistical analysis}

The descriptive results were presented as relative frequency and confidence intervals. Differences in prevalence between sex and age groups were tested by chi-square and confirmed by no overlapping confidence intervals. A complex sample logistic regression model was applied to estimate the odds ratio for PA > $150 \mathrm{~min} /$ week and TV time $>3$ $\mathrm{h}$ /day by marital status (reference group: single) adjusted by age and sex, year of data collection, obesity, hypertension, diabetes, health status and smoking as covariates. All results were estimated using a complex sample model in SPSS software version 25.0 (SPSS Inc., Chicago, IL, USA) applying strata and sample weight provided in the database.

\section{Results}

This study included 561,837 individuals ( $62 \%$ were women). The prevalence of obesity was $18 \%$, diabetes $7 \%$, and hypertension $25 \%$. Smoking was more prevalent in men than in women (14.2\% vs. $9 \%$ ); women had higher prevalence of self-reported poor health than men (5.8\% vs. $3.3 \%$ ) (Table A1). The prevalence of TV time $>3 \mathrm{~h} /$ day was $25.2 \%$ with no sex differences, while PA was significantly higher in men than women ( $43 \%$ vs. $28.2 \%)$ (Table 1). 
Table 1 - Prevalence of TV time, PA, marital status, age, and overweight of the sample by sex.

\begin{tabular}{cccc}
\hline & $\begin{array}{c}\text { All } \\
(\mathbf{n}=5 \mathbf{6 1}, \mathbf{8 3 7})\end{array}$ & $\begin{array}{c}\text { Male } \\
(\mathbf{n}=\mathbf{2 1 2}, \mathbf{4 4 0})\end{array}$ & $\begin{array}{c}\text { Female } \\
(\mathbf{n}=\mathbf{3 4 9}, \mathbf{3 9 7})\end{array}$ \\
\hline TV > 3h/day & $25.2(25.0 ; 25.4)$ & $25.1(24.7 ; 25.5)$ & $25.2(24.9 ; 25.6)$ \\
$\mathbf{P A}>$ 150min/week & $35.0(34.7 ; 35.3)$ & $43.0(42.5 ; 43.4)$ & $28.2(27.9 ; 28.5)$ \\
Age & & & \\
18-30 & $31.5(31.3 ; 31.8)$ & $35.1(34.7 ; 35.6)$ & $28.5(28.1 ; 28.8)$ \\
$31-40$ & $21.4(21.1 ; 21.6)$ & $21.2(20.8 ; 21.6)$ & $21.5(21.2 ; 21.8)$ \\
$41-50$ & $17.8(17.6 ; 18.0)$ & $17.3(17 ; 17.6)$ & $18.3(18 ; 18.5)$ \\
$51-60$ & $14.5(14.3 ; 14.6)$ & $13.6(13.3 ; 13.9)$ & $15.2(15 ; 15.5)$ \\
$61-70$ & $8.6(8.5 ; 8.7)$ & $7.8(7.6 ; 8.0)$ & $9.4(9.2 ; 9.5)$ \\
$71-80$ & $4.5(4.5 ; 4.6)$ & $3.9(3.7 ; 4.0)$ & $5.1(5 ; 5.2)$ \\
$80+$ & $1.6(1.5 ; 1.7)$ & $1.2(1.1 ; 1.3)$ & $2.0(1.9 ; 2.1)$ \\
Marital Status & & & $37.9(37.6 ; 38.3)$ \\
Single & $39.8(39.6 ; 40.1)$ & $42.1(41.6 ; 42.5)$ & $36.7(36.4 ; 37.1)$ \\
Married & $38.5(38.2 ; 38.8)$ & $40.5(40.1 ; 41.0)$ & $10.0(9.8 ; 10.3)$ \\
Divorced & $10.8(10.6 ; 11)$ & $11.7(11.4 ; 12.0)$ & $8.3(8.1 ; 8.4)$ \\
Widower & $5.2(5.1 ; 5.2)$ & $1.5(1.4 ; 1.6)$ & $7(6.9 ; 7.2)$ \\
No reply & $5.7(5.6 ; 5.9)$ & $4.2(4.0 ; 4.4)$ &
\end{tabular}

Data in prevalence $(95 \% \mathrm{CI})$ calculate with complex samples model to estimates the outcome for the population in 27 Brazilian Capitals from 2006 to $2016 .{ }^{*} P<0.05$ - Higher, sex differences.

When stratified by sex and age, the prevalence of TV time $>3 \mathrm{~h} /$ day was higher in men compared to women at most age groups: $31-40$ years (26.2\% vs. $21.5 \%)$, 41-50 years (24.8\% vs. $21.9 \%), 61-70$ years (32.1\% vs. $26.2 \%), 71-80$ years $(34.5 \%$ vs. $28.2 \%)$, and $80+$ years $(37.1 \%$ vs. $27.9 \%)$. Single and married men had lower prevalence of TV time $>3$ $\mathrm{h}$ /day than divorced and widowed ones, while married women had lower prevalence of TV time $>3 \mathrm{~h} /$ day than single, divorced, and widowers.

Prevalence of PA > 150 minutes/week reduced in both men and women from the 1830 to the $80+$ age group (men: $58.6 \%$ vs. $22 \%$; women: $32.3 \%$ vs. $12.6 \%$, respectively). Men had a higher prevalence of PA $>150$ minutes/week than women in all age groups. When stratified by marital status, single men had a higher prevalence of PA > 150 minutes/week than married and divorced ones (54.4\% vs. 34.3\% vs. $35.1 \%$, respectively), while widowers had the lowest prevalence of PA > 150 minutes/week (26\%). Single women had a higher prevalence of PA > 150 minutes/week than married women (30.9\% vs. 28.1\%, respectively), while both single and married women had higher prevalence of PA > 150 minutes/week than divorced (24.7\%) and widower (20.4\%) women. Men had higher prevalence of PA > 150 minutes/week than women independently of marital status (Table 2). 
Table 2 - Prevalence of TV time and PA by sex, age groups, and marital status.

\begin{tabular}{|c|c|c|c|c|}
\hline & \multicolumn{2}{|c|}{ TV $>3 h /$ day } & \multicolumn{2}{|c|}{ PA $>150 \mathrm{~min} /$ week } \\
\hline & Men & Women & Men & Women \\
\hline \multicolumn{5}{|l|}{ Age } \\
\hline $31-40$ & $26.2(25.3 ; 27.1)^{*}$ & $21.5(20.9 ; 22.2)$ & $42.7(41.7 ; 43.8)^{*}$ & $29.1(28.4 ; 29.8)$ \\
\hline $41-50$ & $24.8(23.9 ; 25.7)^{*}$ & $21.9(21.2 ; 22.5)$ & $32.4(31.5 ; 33.3)^{*}$ & $27.3(26.6 ; 27.9)$ \\
\hline $51-60$ & $25.7(24.8 ; 26.7)$ & $26.8(26.1 ; 27.5)$ & $29.9(28.9 ; 30.8)^{*}$ & $27.7(27.0 ; 28.4)$ \\
\hline $71-80$ & $28.2(26.7 ; 29.8)$ & $34.5(33.5 ; 35.5)^{*}$ & $27.7(26.3 ; 29.1)^{*}$ & $19.0(18.2 ; 19.8)$ \\
\hline $80+$ & $27.9(25.3 ; 30.6)$ & $37.1(35.4 ; 38.7)^{*}$ & $22.0(19.8 ; 24.4)^{*}$ & $12.6(11.6 ; 13.7)$ \\
\hline \multicolumn{5}{|l|}{ Marital } \\
\hline \multicolumn{5}{|l|}{ Status } \\
\hline Single & $24.9(24.2 ; 25.5)$ & $25.2(24.7 ; 25.7)$ & $54.4(53.7 ; 55.1)^{*}$ & $30.9(30.4 ; 31.5)$ \\
\hline No reply & $27.3(25.4 ; 29.4)$ & $26.5(25.5 ; 27.6)$ & $40.1(38.0 ; 42.3)^{*}$ & $27.9(27 ; 28.9)$ \\
\hline
\end{tabular}

Data in prevalence $(95 \% \mathrm{CI})$ calculate with a complex samples model to estimates outcomes for the population in 27 Brazilian Capitals from 2009 to $2019 .{ }^{*}$ Higher significantly, sex differences.

Table 3 presents the odds ratio of watching TV more than $3 \mathrm{~h} /$ day and of practicing PA more than 150 minutes/week by age group, marital status, and sex. Married individuals were less likely to watch TV more than $3 \mathrm{~h}$ /day compared to singles in the age groups of 31-40 (men: $\mathrm{OR}=0.79$ vs. women: $\mathrm{OR}=0.75), 41-50$ (men: $\mathrm{OR}=0.66$ vs. women: $\mathrm{OR}=$ 0.68 ), 51-60 (men: $\mathrm{OR}=0.80$ vs. women: $\mathrm{OR}=0.66), 61-70$ (men: $\mathrm{OR}=0.73$ vs. women: $\mathrm{OR}$ $=0.65), 71-80$ (only women: $\mathrm{OR}=0.84$ ), and $80+$ (only women: $\mathrm{OR}=0.59$ ). Also, married individuals had lower odds of watching TV $>3 \mathrm{~h}$ /day than divorced ones in the age groups of 18-30 (men: $\mathrm{OR}=0.65$ vs. women: $\mathrm{OR}=0.69$ ), $31-40$ (men: $\mathrm{OR}=0.73$ vs. women: $\mathrm{OR}=$ 0.72 ), 41-50 (only women: $\mathrm{OR}=0.71$ ), 51-60 (only women: $\mathrm{OR}=0.81$ ), 61-70 (men: $\mathrm{OR}=$ 0.76 vs. women: $\mathrm{OR}=0.79$ ), and $71-80$ (only women: $\mathrm{OR}=0.59$ ).

Regarding PA, married individuals had lower chances of practicing PA $>150$ $\mathrm{min} /$ week compared to singles in the age groups of $18-30$ (men: $\mathrm{OR}=0.59$ vs. women: $\mathrm{OR}$ $=0.74$ ), and 31-40 (only men: $\mathrm{OR}=0.79$ ). However, chances of meeting PA $>150 \mathrm{~min} /$ week were higher in married individuals than in singles in the age groups of 41-50 (only women: $\mathrm{OR}=1.29$ ), 51-60 (only women: $\mathrm{OR}=1.36$ ), 61-70 (only women: $\mathrm{OR}=1.44$ ), and 71-80 (only women: $\mathrm{OR}=1.36$ ). Married individuals had higher chances of meeting PA > $150 \mathrm{~min} /$ week than divorced ones on the age groups of 18-30 (only women: $\mathrm{OR}=1.26$ ), 3140 (only women: $\mathrm{OR}=1.11$ ), 41-50 (men: $\mathrm{OR}=1.14$ vs. women: $\mathrm{OR}=1.21$ ), $51-60$ (only men: $\mathrm{OR}=1.24$ ), 61-70 (men: $\mathrm{OR}=1.24$ vs. women: $\mathrm{OR}=1.21$ ), and 71-80 (only women: $\mathrm{OR}=1.44$ ). Tables $\mathrm{A} 3$ and $\mathrm{A} 4$ describes additional comparisons of the chances of watching $\mathrm{TV}>3 \mathrm{~h}$ /day and meeting PA $>150 \mathrm{~min} /$ week between different marital statuses and sex using single (Table A2) and divorced (Table A3) as references. 
Table 3 - Odds Ratio (OR 95\% CI) of TV time and PA levels for married by age and groups

\begin{tabular}{|c|c|c|c|c|c|}
\hline \multirow{2}{*}{ Age } & \multirow{2}{*}{$\begin{array}{c}\text { Reference } \\
\text { Group }\end{array}$} & \multicolumn{2}{|c|}{$\mathrm{TV}>3 \mathrm{~h} / \mathrm{d}$} & \multicolumn{2}{|c|}{ PA>150min/week } \\
\hline & & Men & Women & Men & Women \\
\hline \multirow{2}{*}{$18-30$} & Single & $1.00(0.88 ; 1.14)$ & $0.99(0.89 ; 1.10)$ & $0.59(0.53 ; 0.66)^{*}$ & $0.74(0.67 ; 0.81)^{*}$ \\
\hline & Divorced & $0.65(0.53 ; 0.78)^{*}$ & $0.69(0.60 ; 0.79)^{*}$ & $0.96(0.81 ; 1.14)$ & $1.26(1.09 ; 1.45)^{*}$ \\
\hline \multirow{2}{*}{$31-40$} & Single & $0.79(0.71 ; 0.88)^{*}$ & $0.75(0.69 ; 0.82)^{*}$ & $0.79(0.72 ; 0.87)^{*}$ & $0.93(0.86 ; 1.00)$ \\
\hline & Divorced & $0.73(0.63 ; 0.84)^{*}$ & $0.72(0.64 ; 0.82)^{*}$ & $1.03(0.91 ; 1.17)$ & $1.11(0.99 ; 1.24)^{*}$ \\
\hline \multirow{2}{*}{$41-50$} & Single & $0.66(0.58 ; 0.75)^{*}$ & $0.68(0.62 ; 0.75)^{*}$ & $0.98(0.88 ; 1.09)$ & $1.29(1.18 ; 1.40)^{*}$ \\
\hline & Divorced & $0.93(0.80 ; 1.07)$ & $0.71(0.63 ; 0.81)^{*}$ & $1.14(1.01 ; 1.28)^{*}$ & $1.21(1.08 ; 1.35)^{*}$ \\
\hline \multirow{2}{*}{$51-60$} & Single & $0.80(0.69 ; 0.93)^{*}$ & $0.66(0.60 ; 0.73)^{*}$ & $0.93(0.80 ; 1.07)$ & $1.36(1.24 ; 1.49)^{*}$ \\
\hline & Divorced & $0.88(0.75 ; 1.03)$ & $0.81(0.71 ; 0.93)^{*}$ & $1.24(1.07 ; 1.42)^{*}$ & $1.13(0.99 ; 1.30)$ \\
\hline \multirow{2}{*}{$61-70$} & Single & $0.73(0.58 ; 0.92)^{*}$ & $0.65(0.58 ; 0.73)^{*}$ & $0.98(0.81 ; 1.19)$ & $1.44(1.29 ; 1.60)^{*}$ \\
\hline & Divorced & $0.76(0.61 ; 0.93)^{*}$ & $0.79(0.66 ; 0.95)^{*}$ & $1.24(1.03 ; 1.50)^{*}$ & $1.21(1.00 ; 1.47)^{*}$ \\
\hline \multirow{2}{*}{$71-80$} & Single & $1.00(0.72 ; 1.38)$ & $0.84(0.73 ; 0.98)^{*}$ & $1.28(0.90 ; 1.82)$ & $1.36(1.15 ; 1.61)^{*}$ \\
\hline & Divorced & $0.87(0.62 ; 1.20)$ & $0.79(0.66 ; 0.95)^{*}$ & $1.30(0.99 ; 1.71)$ & $1.44(1.01 ; 2.04)^{*}$ \\
\hline \multirow{2}{*}{$80+$} & Single & $0.83(0.41 ; 1.67)$ & $0.59(0.45 ; 0.79)^{*}$ & $1.16(0.59 ; 2.27)$ & $0.91(0.61 ; 1.36)$ \\
\hline & Divorced & $1.00(0.60 ; 1.66)$ & $0.92(0.67 ; 1.26)$ & $1.05(0.61 ; 1.81)$ & $1.09(0.46 ; 2.59)$ \\
\hline
\end{tabular}

Complex Sample Logistical Regression. CI: confidence Interval. OR: (CI 95\%) ${ }^{*} P<0.05$.

\section{Discussion}

Our study aimed to identify the magnitude of independent associations between marriage and other marital statuses with physical activity and TV time. The main findings of this study were:

(a) TV time $>3 \mathrm{~h} /$ day was more prevalent in younger men and in older women;

(b) The prevalence of PA > 150 minutes/week decreased with age, and in general, men were more active than women;

(c) married men and women had lower odds of watching TV $>3 \mathrm{~h} /$ day than single and divorced ones in most age groups, especially women;

(d) married men and women in younger age groups were less likely to practice PA for more than 150 minutes/week levels than single ones, but among those older than 40, married women had higher odds of meeting PA levels than single ones;

(e) married women had higher chances of practicing PA $>150$ minutes/week than divorced ones in most age groups, while middle age (41-70 years) married men had higher chances of practicing PA > 150 minutes/week than divorced middle age men.

More than a fourth of the individuals watched TV more than three hours a day. Three or more hours of TV time/day is associated with increased mortality risk [21]. Current lifestyles in society provide many opportunities for leisure-time sedentary behavior like watching too much TV. Elevated levels of sedentary behavior increase the risk of metabolic dysfunctions such as dyslipidemia and insulin resistance, and have deleterious effects for bone and cardiovascular health [22]. Each 1-hour increment in total sitting time increases the risk of having sarcopenia by $33 \%$. However, only TV time was associated with lower levels of lean body mass [23]. Watching TV is not only a sedentary behavior but is also linked to other health risk behaviors such as unhealthy diet with higher consumption of energy-dense foods and fewer fruits and vegetables [24].

Interestingly, TV time $>3$ hours/day was more prevalent in younger men and in older women. Nathanson et al. [25] provides a theoretical framework on the topic, where men are more likely to watch TV for goal-directed purposes, such as viewing the news while women are more likely to watch TV as a substitute for social interaction. As women 
tend to live longer than men [26], it is likely that women increase TV use to replace their partner's social interaction.

Our results showed that $35 \%$ of individuals practiced more than $150 \mathrm{~min} /$ week of leisure-time PA. In contrast, Rech et al. [27] found that only $18,8 \%$ of the individuals in their study practiced more than $150 \mathrm{~min} /$ week of leisure-time PA, probably because the study was conducted in a single capital city. Similarly to our findings, women were less active than men in the study conducted by Guthold et al. [13]. They found that lower levels of physical activity were more prevalent in women in Latin America and the Caribbean compared to other continents. This might be due to differences between sexes because of factors such as competition and challenges, or extrinsic factors such as self-efficacy and social values regarding physical appearance [28]. Recent finds suggest that PA levels have a dose-response relationship with reduced risk of all-cause mortality $[21,29,30]$, and while sitting time increases the risk of all-cause mortality, PA mitigates the increased risk [21]. Single men and women had higher prevalence of PA $>150$ minutes/week than married counterparts. This was not expected based on our hypothesis that married individuals would have a healthier lifestyle. However, this might be because married individuals have reduced free time to practice leisure-time PA. Further investigations are required to confirm if married individuals indeed have reduced free time and, if so, comprehend its causes and find alternatives for active lifestyles among those who are married.

Married individuals were less likely to watch TV $>3$ hours/day than single and divorced ones in most age groups. This could be because married individuals have either increased hours of work or increased hours of house chores [31]. Married and divorced younger men and women were less likely to meet the PA guidelines levels. However, married women over 40 were more likely to meet PA levels.

It is necessary to recognize our study limitations. Our sample represents the population from Brazilian capital cities and the federal district (urban areas); people living in these areas likely have lower levels of PA compared to rural areas not assessed [32]. Also, our study investigated leisure-time PA; people living in low-to-middle income countries have high PA in their occupation, for transportation (e.g. walking, cycling), and household chores [4], and the daily physical demands limits the individuals energy to perform leisure-time PA [33]. In addition, our data is from a self-reported telephone survey. Inaccurate reporting bias the results for reasons such as embarrassment, lack of interest, or the inability to report PA levels accurately. Also, it is possible that the quality of the relationships among married people could interfere in the results, and different experiences exist among unmarried people since they are not a homogenous group [5].

\section{Conclusions}

Our study found that viewing TV more than three hours a day was prevalent in more than a fourth of our sample, and there were no differences by sex or age. The highest prevalence was found in younger men and in older women. Married men and women were less likely to watch TV more than three hours a day in most age groups. Only $35 \%$ of participants met the PA recommended levels (>150 minutes/week), and younger married men and women are less likely to meet these levels. However, women 40 years old or older were more likely to reach PA levels than single women.

Author Contributions: Conceptualization, T.G.C. and N.G.L.S; methodology, T.G.C. and N.G.L.S.; formal analysis, T.G.C; investigation, T.G.C.; resources, T.G.C.; data curation, T.G.C. and N.G.L.S.; writing-original draft preparation, T.G.C. and H.S.J.; writing-review and editing, T.G.C., N.G.L.S., M.R.Q., M.P.S., E.S.C., H.S.J., and E.R.V.; visualization, X.X.; supervision, T.G.C. and H.S.J.; project administration, T.G.C.; All authors have read and agreed to the published version of the manuscript.

Data Availability Statement: The data that support this article can be found at the Brazilian Ministry of Health website at http://svs.aids.gov.br/download/Vigitel/ from the Surveillance of Risk and Protection Factors for Chronic Diseases by Telephone Survey - VIGITEL section. 
Acknowledgments: This study was financed in part by the CAPES (Coordenação de Aperfeiçoamento de Pessoal de Nível Superior - Brasil). N.G.L.S. is a research fellow during graduation program. - Finance Code 001.

Conflicts of Interest: The authors declare they have no actual or potential competing financial interests.

\section{Appendix A}

Table A1 - Covariates prevalence of obesity, smoking, hypertension, diabetes, and poor self-evaluation of health status stratified by sex

\begin{tabular}{ccccccc}
\hline & \multicolumn{2}{c}{ All } & \multicolumn{2}{c}{ Male } & \multicolumn{2}{c}{ Female } \\
& $\mathbf{\%}$ & $\mathbf{9 5 \%} \mathbf{C I}$ & $\mathbf{\%}$ & $\mathbf{9 5 \%} \mathbf{C I}$ & $\mathbf{\%}$ & $\mathbf{9 5 \%}$ CI \\
\hline Obese & 17.8 & $(17.6 ; 18,0)$ & 17.2 & $(16.9 ; 17.6)$ & 18.3 & $(18.0 ; 18.5)$ \\
Smoker & 11.4 & $(11.2 ; 11,6)$ & 14.2 & $(13.9 ; 14.6)$ & 9.0 & $(8.8 ; 9.2)$ \\
Hypertensive & 24.7 & $(24.7 ; 24,9)$ & 21.9 & $(21.6 ; 22.3)$ & 27.0 & $(26.7 ; 27.3)$ \\
Diabetic & 7.3 & $(7.2 ; 7,5)$ & 6.7 & $(6.5 ; 6.9)$ & 7.9 & $(7.7 ; 8.0)$ \\
PSE Health & 4,6 & $(4.5 ; 4,7)$ & 3.3 & $(3.1 ; 3.4)$ & 5.8 & $(5.6 ; 5.9)$ \\
\hline
\end{tabular}

PSE Health Status: Poor self-evaluation of health status. CI: confidence Interval

Table A2 - Odds Ratio (OR 95\% CI) of TV time and PA levels by age groups, marital status (reference group: single), and sex.

\begin{tabular}{cccccc}
\hline \multirow{2}{*}{ Age } & Marital Status & Men & Women & Men & Women \\
\hline \multirow{2}{*}{$18-30^{1}$} & Married & $1.00(0.88 ; 1.14)$ & $0.99(0.89 ; 1.10)$ & $0.59(0.53 ; 0.66)^{*}$ & $0.74(0.67 ; 0.81)^{*}$ \\
& Divorced & $1.55(1.33 ; 1.81)^{*}$ & $1.45(1.29 ; 1.62)^{*}$ & $0.62(0.54 ; 0.71)^{*}$ & $0.59(0.52 ; 0.66)^{*}$ \\
\hline \multirow{2}{*}{$31-40$} & Married & $0.79(0.71 ; 0.88)^{*}$ & $0.75(0.69 ; 0.82)^{*}$ & $0.79(0.72 ; 0.87)^{*}$ & $0.93(0.86 ; 1.00)$ \\
& Divorced & $1.09(0.94 ; 1.25)$ & $1.04(0.92 ; 1.17)$ & $0.77(0.67 ; 0.87)^{*}$ & $0.84(0.75 ; 0.94)^{*}$ \\
& Widower & $1.77(0.83 ; 3.76)$ & $1.02(0.71 ; 1.47)$ & $0.57(0.26 ; 1.29)$ & $1.25(0.90 ; 1.75)$ \\
\hline \multirow{2}{*}{$41-50$} & Married & $0.66(0.58 ; 0.75)^{*}$ & $0.68(0.62 ; 0.75)^{*}$ & $0.98(0.88 ; 1.09)$ & $1.29(1.18 ; 1.40)^{*}$ \\
& Divorced & $0.71(0.60 ; 0.84)^{*}$ & $0.95(0.84 ; 1.08)$ & $0.86(0.75 ; 0.99)^{*}$ & $1.06(0.94 ; 1.20)$ \\
& Widower & $0.67(0.41 ; 1.11)$ & $1.14(0.93 ; 1.40)$ & $0.61(0.37 ; 0.98)^{*}$ & $1.10(0.89 ; 1.38)$ \\
\hline \multirow{2}{*}{$51-60$} & Married & $0.80(0.69 ; 0.93)^{*}$ & $0.66(0.60 ; 0.73)^{*}$ & $0.93(0.80 ; 1.07)$ & $1.36(1.24 ; 1.49)^{*}$ \\
& Divorced & $0.90(0.74 ; 1.10)$ & $0.81(0.71 ; 0.94)^{*}$ & $0.75(0.62 ; 0.90)^{*}$ & $1.20(1.04 ; 1.39)^{*}$ \\
& Widower & $1.12(0.76 ; 1.65)$ & $0.95(0.83 ; 1.09)$ & $0.70(0.49 ; 1.01)$ & $1.10(0.96 ; 1.26)$ \\
\hline \multirow{2}{*}{$61-70$} & Married & $0.73(0.58 ; 0.92)^{*}$ & $0.65(0.58 ; 0.73)^{*}$ & $0.98(0.81 ; 1.19)$ & $1.44(1.29 ; 1.60)^{*}$ \\
& Divorced & $0.96(0.72 ; 1.29)$ & $0.82(0.68 ; 1.00)$ & $0.79(0.61 ; 1.02)$ & $1.19(0.97 ; 1.46)$ \\
& Widower & $0.96(0.68 ; 1.35)$ & $0.88(0.78 ; 0.99)^{*}$ & $1.08(0.80 ; 1.45)$ & $1.15(1.02 ; 1.30)^{*}$ \\
\hline \multirow{2}{*}{$71-80$} & Married & $1.00(0.72 ; 1.38)$ & $0.84(0.73 ; 0.98)^{*}$ & $1.28(0.90 ; 1.82)$ & $1.36(1.15 ; 1.61)^{*}$ \\
& Divorced & $1.15(0.74 ; 1.80)$ & $0.92(0.66 ; 1.28)$ & $0.98(0.64 ; 1.51)$ & $0.95(0.66 ; 1.37)$ \\
& Widower & $1.15(0.78 ; 1.69)$ & $1.07(0.93 ; 1.23)$ & $1.08(0.71 ; 1.64)$ & $1.17(0.99 ; 1.38)$ \\
\hline \multirow{2}{*}{$80+$} & Married & $0.83(0.41 ; 1.67)$ & $0.59(0.45 ; 0.79)^{*}$ & $1.16(0.59 ; 2.27)$ & $0.91(0.61 ; 1.36)$ \\
& Divorced & $0.83(0.36 ; 1.91)$ & $0.93(0.49 ; 1.76)$ & $1.11(0.48 ; 2.55)$ & $0.83(0.34 ; 2.05)$ \\
& Widower & $0.80(0.39 ; 1.63)$ & $1.01(0.80 ; 1.26)$ & $1.26(0.62 ; 2.59)$ & $0.75(0.53 ; 1.07)$ \\
\hline
\end{tabular}

Reference Group: Divorced; Complex Sample Logistical Regression. ${ }^{1:}$ small prevalence of widower. ${ }^{*} P<0.05$ 
Table A3 - Odds Ratio (OR 95\% CI) of TV time and PA levels by age groups, marital status (reference group: divorced), and sex.

\begin{tabular}{|c|c|c|c|c|c|}
\hline \multirow{2}{*}{ Age } & \multirow{2}{*}{ Marital Status } & \multicolumn{2}{|c|}{$\mathrm{TV}>3 \mathrm{~h} / \mathrm{d}$} & \multicolumn{2}{|c|}{ PA>150min/week } \\
\hline & & Men & Women & Men & Women \\
\hline \multirow{2}{*}{$18-30^{1}$} & Single & $0.65(0.55 ; 0.75)^{*}$ & $0.69(0.62 ; 0.78)^{*}$ & $1.62(1.41 ; 1.87)^{*}$ & $1.71(1.52 ; 1.92)^{*}$ \\
\hline & Married & $0.65(0.53 ; 0.78)^{*}$ & $0.69(0.60 ; 0.79)^{*}$ & $0.96(0.81 ; 1.14)$ & $1.26(1.09 ; 1.45)^{*}$ \\
\hline \multirow{3}{*}{$31-40$} & Single & $0.92(0.80 ; 1.06)$ & $0.96(0.86 ; 1.08)$ & $1.31(1.15 ; 1.48)^{*}$ & $1.20(1.07 ; 1.34)^{*}$ \\
\hline & Married & $0.73(0.63 ; 0.84)^{*}$ & $0.72(0.64 ; 0.82)^{*}$ & $1.03(0.91 ; 1.17)$ & $1.11(0.99 ; 1.24)$ \\
\hline & Widower & $1.63(0.76 ; 3.48)$ & $0.98(0.68 ; 1.43)$ & $0.75(0.33 ; 1.69)$ & $1.50(1.06 ; 2.11)^{*}$ \\
\hline \multirow{3}{*}{$41-50$} & Single & $1.40(1.19 ; 1.65)^{*}$ & $1.05(0.93 ; 1.20)$ & $1.16(1.01 ; 1.34)^{*}$ & $0.94(0.83 ; 1.06)$ \\
\hline & Married & $0.93(0.80 ; 1.07)$ & $0.71(0.63 ; 0.81)^{*}$ & $1.14(1.01 ; 1.28)^{*}$ & $1.21(1.08 ; 1.35)^{*}$ \\
\hline & Widower & $0.94(0.57 ; 1.57)$ & $1.20(0.97 ; 1.49)$ & $0.70(0.43 ; 1.14)$ & $1.04(0.82 ; 1.31)$ \\
\hline \multirow{3}{*}{$51-60$} & Single & $1.11(0.91 ; 1.35)$ & $1.23(1.06 ; 1.42)^{*}$ & $1.34(1.11 ; 1.61)^{*}$ & $0.83(0.72 ; 0.96)^{*}$ \\
\hline & Married & $0.88(0.75 ; 1.03)$ & $0.81(0.71 ; 0.93)^{*}$ & $1.24(1.07 ; 1.42)^{*}$ & $1.13(0.99 ; 1.30)$ \\
\hline & Widower & $1.24(0.84 ; 1.83)$ & $1.17(0.99 ; 1.38)$ & $0.94(0.65 ; 1.34)$ & $0.91(0.77 ; 1.08)$ \\
\hline \multirow{3}{*}{$61-70$} & Single & $1.04(0.77 ; 1.39)$ & $1.22(1.00 ; 1.48)$ & $1.27(0.98 ; 1.64)$ & $0.84(0.69 ; 1.04)$ \\
\hline & Married & $0.76(0.61 ; 0.93)^{*}$ & $0.79(0.66 ; 0.95)^{*}$ & $1.24(1.03 ; 1.50)^{*}$ & $1.21(1.00 ; 1.47)$ \\
\hline & Widower & $0.99(0.71 ; 1.38)$ & $1.07(0.88 ; 1.29)$ & $1.37(1.02 ; 1.84)^{*}$ & $0.97(0.80 ; 1.19)$ \\
\hline \multirow{3}{*}{$71-80$} & Single & $0.87(0.56 ; 1.36)$ & $1.22(1.00 ; 1.48)$ & $1.02(0.66 ; 1.57)$ & $1.06(0.73 ; 1.53)$ \\
\hline & Married & $0.87(0.62 ; 1.20)$ & $0.79(0.66 ; 0.95)^{*}$ & $1.30(0.99 ; 1.71)$ & $1.44(1.01 ; 2.04)^{*}$ \\
\hline & Widower & $1.00(0.68 ; 1.48)$ & $1.07(0.88 ; 1.29)$ & $1.10(0.78 ; 1.57)$ & $1.24(0.87 ; 1.75)$ \\
\hline \multirow{3}{*}{$80+$} & Single & $1.20(0.52 ; 2.77)$ & $1.09(0.78 ; 1.51)$ & $0.91(0.39 ; 2.09)$ & $1.20(0.49 ; 2.95)$ \\
\hline & Married & $1.00(0.60 ; 1.66)$ & $0.92(0.67 ; 1.26)$ & $1.05(0.61 ; 1.81)$ & $1.09(0.46 ; 2.59)$ \\
\hline & Widower & $0.96(0.56 ; 1.64)$ & $1.17(0.85 ; 1.60)$ & $1.14(0.62 ; 2.10)$ & $0.90(0.39 ; 2.09)$ \\
\hline
\end{tabular}

Reference Group: Divorced; Complex Sample Logistical Regression. ${ }^{1:}$ small prevalence of widower; ${ }^{*} P<0.05$

\section{References}

1. Pedersen, B.K.; Saltin, B. Exercise as medicine - Evidence for prescribing exercise as therapy in 26 different chronic diseases. Scand. J. Med. Sci. Sport. 2015, 25 Suppl., 1-72, doi:10.1111/sms.12581.

2. De Rezende, L.F.M.; Lopes, M.R.; Rey-Loṕez, J.P.; Matsudo, V.K.R.; Luiz, O.D.C. Sedentary behavior and health outcomes: An overview of systematic reviews. PLoS One 2014, 9, doi:10.1371/journal.pone.0105620.

3. Bull, F.; Al-Ansari, S.; Biddle, S.; Borodulin, K.; Buman, M.; Cardon, G.; Carty, C.; Chaput, J.-P.; Chastin, S.; Chou, R.; et al. World Health Organization 2020 Guidelines on Physical Activity and Sedentary Behaviour. Br. J. Sports Med. 2020, 54, 14511462, doi:10.1136/bjsports-2020-102955.

4. Bauman, A.E.; Reis, R.S.; Sallis, J.F.; Wells, J.C.; Loos, R.J.F.; Martin, B.W.; Alkandari, J.R.; Andersen, L.B.; Blair, S.N.; Brownson, R.C.; et al. Correlates of physical activity: Why are some people physically active and others not? Lancet 2012, 380, 258-271, doi:10.1016/S0140-6736(12)60735-1.

5. Robards, J.; Evandrou, M.; Falkingham, J.; Vlachantoni, A. Marital status, health and mortality. Maturitas 2012, 73, 295-299, doi:10.1016/j.maturitas.2012.08.007.

6. Kyung-Sook, W.; SangSoo, S.; Sangjin, S.; Young-Jeon, S. Marital status integration and suicide: A meta-analysis and metaregression. Soc. Sci. Med. 2018, 197, 116-126, doi:10.1016/j.socscimed.2017.11.053.

7. Kim, A.; Lee, J.A.; Park, H.S. Health behaviors and illness according to marital status in middle-aged Koreans. J. Public Health 
(Oxf). 2018, 40, e99-e106, doi:10.1093/pubmed/fdx071.

8. Roelfs, D.J.; Shor, E.; Kalish, R.; Yogev, T. The rising relative risk of mortality for singles: Meta-analysis and meta-regression. Am. J. Epidemiol. 2011, 174, 379-389, doi:10.1093/aje/kwr111.

9. Salvatore, J.E.; Gardner, C.O.; Kendler, K.S. Marriage and reductions in men's alcohol, tobacco, and cannabis use. Psychol. Med. 2020, 50, 2634-2640, doi:10.1017/S0033291719002964.

10. Joung, I.M.A.; Van De Mheen, H.D.; Stronks, K.; Van Poppel, F.W.A.; Mackenbach, J.P. A longitudinal study of health selection in marital transitions. Soc. Sci. Med. 1998, 46, 425-435, doi:10.1016/S0277-9536(97)00186-X.

11. Ortega, F.B.; Brown, W.J.; Lee, D.C.; Baruth, M.; Sui, X.; Blair, S.N. In fitness and health? A prospective study of changes in marital status and fitness in men and women. Am. J. Epidemiol. 2011, 173, 337-344, doi:10.1093/aje/kwq362.

12. Ferreira, A.P. de S.; Szwarcwald, C.L.; Damacena, G.N. Prevalence of obesity and associated factors in the Brazilian population: a study of data from the 2013 National Health Survey. Brazilian J. Epidemiol. 2019, 22, e190024, doi:10.1590/1980549720190024.

13. Guthold, R.; Stevens, G.A.; Riley, L.M.; Bull, F.C. Worldwide trends in insufficient physical activity from 2001 to 2016 : a pooled analysis of 358 population-based surveys with 1.9 million participants. Lancet Glob. Heal. 2018, 6, E1077-E1086, doi:10.1016/S2214-109X(18)30357-7.

14. Hansen, B.H.; Kolle, E.; Dyrstad, S.M.; Holme, I.; Anderssen, S.A. Accelerometer-Determined Physical Activity in Adults and Older People. Med. Sci. Sports Exerc. 2012, 44, 266-272, doi:10.1249/MSS.0b013e31822cb354.

15. Rocha, B.M.C.; Goldbaum, M.; César, C.L.G.; Stopa, S.R. Sedentary behavior in the city of São Paulo, Brazil: ISA-Capital 2015. Rev. Bras. Epidemiol. 2019, 22, E190050, doi:10.1590/1980-549720190050.

16. O’Donoghue, G.; Perchoux, C.; Mensah, K.; Lakerveld, J.; Van Der Ploeg, H.; Bernaards, C.; Chastin, S.F.M.; Simon, C.; O'Gorman, D.; Nazare, J.A. A systematic review of correlates of sedentary behaviour in adults aged 18-65 years: A socioecological approach. BMC Public Health 2016, 16, doi:10.1186/s12889-016-2841-3.

17. Rhodes, R.E.; Janssen, I.; Bredin, S.S.D.; Warburton, D.E.R.; Bauman, A. Physical activity: Health impact, prevalence, correlates and interventions. Psychol. Heal. 2017, 32, 942-975, doi:10.1080/08870446.2017.1325486.

18. Choi, J.; Lee, M.; Lee, J.K.; Kang, D.; Choi, J.Y. Correlates associated with participation in physical activity among adults: A systematic review of reviews and update. BMC Public Health 2017, 17, 356, doi:10.1186/s12889-017-4255-2.

19. Ministério da Saúde Vigitel Brasil 2009: vigilância de fatores de risco e proteção para doenças crônicas por inquérito telefônico [Internet]; Brasília, DF, 2013;

20. World Health Organization Physical status: the use and interpretation of anthropometry; Geneva, 1995;

21. Ekelund, U.; Steene-Johannessen, J.; Brown, W.J.; Fagerland, M.W.; Owen, N.; Powell, K.E.; Bauman, A.; Lee, I.M.; Ding, D.; Heath, G.; et al. Does physical activity attenuate, or even eliminate, the detrimental association of sitting time with mortality? A harmonised meta-analysis of data from more than 1 million men and women. Lancet 2016, 388, 1302-1310, doi:10.1016/S0140-6736(16)30370-1.

22. Tremblay, M.S.; Colley, R.C.; Saunders, T.J.; Healy, G.N.; Owen, N. Physiological and health implications of a sedentary lifestyle. Appl. Physiol. Nutr. Metab. 2010, 35, 725-740, doi:10.1139/H10-079.

23. Gianoudis, J.; Bailey, C.A.; Daly, R.M. Associations between sedentary behaviour and body composition, muscle function and sarcopenia in community-dwelling older adults. Osteoporos. Int. 2014, 26, 571-579, doi:10.1007/s00198-014-2895-y.

24. Biddle, S.J.H.; Bengoechea García, E.; Pedisic, Z.; Bennie, J.; Vergeer, I.; Wiesner, G. Screen Time, Other Sedentary Behaviours, and Obesity Risk in Adults: A Review of Reviews. Curr. Obes. Rep. 2017, 6, 134-147, doi:10.1007/s13679-017-0256-9.

25. Nathanson, A.I.; Perse, E.M.; Ferguson, D.A. Gender differences in television use: An exploration of the instrumentalexpressive dichotomy. Commun. Res. Reports 1997, 14, 176-188, doi:10.1080/08824099709388659.

26. United Nations World Population Prospects 2019 Available https://population.un.org/wpp2019/Download/Standard/Interpolated/ (accessed on Dec 21, 2020). 
from Curitiba, Brazil. Prev. Med. (Baltim). 2014, 58, 53-57, doi:10.1016/j.ypmed.2013.10.023.

28. Rosenfeld, C.S. Sex-dependent differences in voluntary physical activity. J. Neurosci. Res. 2017, 95, 279-290, doi:10.1002/jnr.23896.

29. Stamatakis, E.; Gale, J.; Bauman, A.; Ekelund, U.; Hamer, M.; Ding, D. Sitting Time, Physical Activity, and Risk of Mortality in Adults. J. Am. Coll. Cardiol. 2019, 73, 2062-2072, doi:10.1016/j.jacc.2019.02.031.

30. Warburton, D.E.R.; Bredin, S.S.D. Health benefits of physical activity: A systematic review of current systematic reviews. Curr. Opin. Cardiol. 2017, 32, 541-556, doi:10.1097/HCO.0000000000000437.

31. Uhr, D. de A.P.; Ely, R.A.; Cardoso, R.P.; Uhr, J.G.Z. Allocation of time between genders and the labor market: an analysis between Married and single to Brazil. Nov. Econ. 2019, 29, 1041-1063, doi:10.1590/0103-6351/4268.

32. Sallis, J.F.; Bull, F.; Guthold, R.; Heath, G.W.; Inoue, S.; Kelly, P.; Oyeyemi, A.L.; Perez, L.G.; Richards, J.; Hallal, P.C. Progress in physical activity over the Olympic quadrennium. Lancet 2016, 388, 1325-1336, doi:10.1016/S0140-6736(16)30581-5.

33. Guthold, R.; Louazani, S.A.; Riley, L.M.; Cowan, M.J.; Bovet, P.; Damasceno, A.; Sambo, B.H.; Tesfaye, F.; Armstrong, T.P. Physical activity in 22 African countries: Results from the world health organization STEPwise approach to chronic disease risk factor surveillance. Am. J. Prev. Med. 2011, 41, 52-60, doi:10.1016/j.amepre.2011.03.008. 